\title{
Retinal dialysis
}

\author{
A. H. GHIGNELL
}

Moorfields Eye Hospital, City Road, London, E.C.I

Retinal dialysis is an important cause of retinal detachment and subsequent reduction of vision in the younger age groups. Dufour (1969) found that up to the age of 20 years such cases form 8 to ro per cent. of all cases of retinal detachment. Leffertstra (I950) and Hagler and North ( 1968 ) have analysed groups of patients with dialysis and have described the clinical features of detachments caused by this type of retinal hole.

In the surgical treatment of detachment due to dialysis, the value of encirclement procedures combined with drainage of subretinal fluid has been stressed by Hagler and North (I968), Hudson (1965), and Cox, Schepens, and Freeman (1966). Blach and Davies ( 1967 ) suggested that, for most dialyses, a local procedure may be used, but for giant dialyses an encircling procedure was advised.

Lincoff and Kreissig (1972) and Scott (1970) have advocated the avoidance of drainage of subretinal fluid in the treatment of retinal detachments, as this removes many of the serious complications (e.g. choroidal haemorrhage) of retinal surgery. Nadel, Gieser, and Lincoff ( I 97 I) successfully treated seventeen cases of retinal detachment due to dialysis with external plombage and cryotherapy without drainage of subretinal fluid. Lccal procedures are advantageous because they largely avoid the various degrees of anterior segment ischaemia described by Crock ( 1967 ) that may be expected after encirclement procedures. The purpose of the present paper is to report the results of treatment of 62 consecutive cases of retinal dialysis. In order to investigate the efficacy of the procedure, a prospective series of twenty cases was treated with local plombage without drainage of subretinal fluid, and the results were compared with those in 44 cases treated with drainage of subretinal fluid. Various aspects of the surgical technique of external plombage and cryotherapy as used in these operations are described.

\section{Materials}

The patients studied were those admitted to Moorfiel ds Eye Hospital, Highgate Annexe, between 1966 and 1970. The 62 patients represent 8 per cent. of the total number of 824 cases of primary detachment operated on during these years. There were four bilateral cases, making a total of 66 eyes that received treatment. Of the 66 eyes, 64 had an associated retinal detachment. The minimum follow-up period was I year from the time of surgery.

\section{Results}

Sex, age group, and affected eye

Men outnumbered women in the series studied by 48 (77 per cent.) to 14 ( 23 per cent.), as shown in Table I (opposite). This Table also shows that 26 cases (42 per cent.) occurred in patients under 20 years of age, and that the right eye was predominantly affected, with a bilateral incidence of 6 per cent. 
Table I Sex, age group, and affected eye in 62 cases of retinal dialysis

\begin{tabular}{|c|c|c|c|c|c|c|c|c|c|c|c|c|c|}
\hline \multicolumn{4}{|l|}{ Sex } & \multicolumn{4}{|c|}{ Age group (yrs) } & \multicolumn{4}{|c|}{ Eye affected } & \multirow{2}{*}{\multicolumn{2}{|c|}{ Both }} \\
\hline \multicolumn{2}{|c|}{ Male } & \multicolumn{2}{|c|}{ Female } & \multicolumn{2}{|c|}{ Under 20} & \multicolumn{2}{|c|}{ Over 20} & \multicolumn{2}{|c|}{ Right } & \multicolumn{2}{|l|}{ Left } & & \\
\hline No. & $\begin{array}{l}\text { Per } \\
\text { cent. }\end{array}$ & No. & $\begin{array}{l}\text { Per } \\
\text { cent. }\end{array}$ & No. & $\begin{array}{l}\text { Per } \\
\text { cent. }\end{array}$ & No. & $\begin{array}{l}\text { Per } \\
\text { cent. }\end{array}$ & No. & $\begin{array}{l}\text { Per } \\
\text { cent. }\end{array}$ & No. & $\begin{array}{l}\text { Per } \\
\text { cent. }\end{array}$ & No. & $\begin{array}{l}\text { Per } \\
\text { cent. }\end{array}$ \\
\hline 48 & 77 & 14 & 23 & 26 & $4^{2}$ & 36 & $5^{8}$ & 40 & 65 & 18 & 29 & 4 & 6 \\
\hline
\end{tabular}

\section{Refractive error}

Sixty eyes ( 92 per cent.) were emmetropic and myopia was present in only four $(6$ per cent.) of the treated eyes. One patient was aphakic.

\section{Duration of detachment}

The duration of detachment was estimated from the history and from the presence of pigmented demarcation lines which Leffertstra (1950) estimated to take about 3 months to appear (Table II). It can be seen that, in 48 ( 74 per cent.) of the 64 eyes, the detachments were estimated to be between 2 weeks and I year old. The presence of secondary intraretinal cysts, further evidence of longstanding retinal detachment, were found in only six eyes (9 per cent.).

\section{Macular detachment}

In the 64 cases of retinal detachment, the macula was found to be detached preoperatively in 53 cases ( 84 per cent.). In nearly all cases the upper limit of the detachment rose to just above the level of the macula.

Table II Duration of detachment in 64 eyes with retinal dialysis

\begin{tabular}{lcc}
\hline Duration & & No. of eyes \\
\cline { 3 - 3 } Less than 2 wks & & 9 \\
2 wks - 3 mths & 26 \\
3 mths - I yr & 22 \\
Longer than I yr & 7 \\
\hline
\end{tabular}

Table III Methods used in the surgical treatment of 66 eyes with retinal dialysis

\begin{tabular}{|c|c|c|}
\hline \multirow{2}{*}{ Surgical method } & \multicolumn{2}{|c|}{ Eyes } \\
\hline & No. & Per cent. \\
\hline $\begin{array}{l}\text { Encirclement and drainage of } \\
\text { subretinal fluid } \\
\text { Local buckle and drainage of }\end{array}$ & 19 & 28 \\
\hline $\begin{array}{l}\text { subretinal fluid } \\
\text { Local buckle without drainage }\end{array}$ & 25 & 36 \\
\hline $\begin{array}{l}\text { of subretinal fluid } \\
\text { Photocoagulation only }\end{array}$ & $\begin{array}{r}20 \\
2\end{array}$ & $\begin{array}{r}33 \\
3\end{array}$ \\
\hline
\end{tabular}

\section{OPERATIVE PROCEDURES}

The procedures used are summarized in Table III. It can be seen that nineteen eyes were treated by an encircling procedure, and six of these also had a local implant to increase the size of the buckle in the region of dialysis. In encirclement procedures, an episcleral silicone band was always used. 45 cases were treated with local episcleral sponge implant only, and of these twenty consecutive cases were treated without drainage of subretinal fluid.

SURGICAL TEGHNIQUE

Silastic sponge implants have been used in all cases treated by local procedure. Either a 
$3 \mathrm{~mm}$. or $5 \mathrm{~mm}$. sponge placed circumferentially was employed according to the size of the dialyses.

\section{Placement of sponge}

The indent was produced with the highest point of the buckle just posterior to the edge of the dialysis. This was to achieve adhesion between the detached part of the retina and the pigment epithelium just behind the dialysis edge, the retracted apex of which often remained elevated following surgery. To prevent subsequent anterior leakage of fluid, the ends of the buckle should extend to the ora serrata at the limits of the dialysis. In small dialyses the placement of the sponge as described usually completely filled the dialysis in addition to producing a buckle posterior to the dialysis edge. In large dialyses, however, in order to produce a buckle posterior to the edge of the dialysis, particularly near the apex, the sponge was curved with the apex further from the limbus than the ends (Fig. I). In these cases the dialysis itself came to rest on the anterior slope of the buckle. When subretinal fluid was not drained it was difficult to correctly estimate the position of the apex of the buckle in relationship to the dialysis edge, as apposition was not always achieved at the time of surgery.
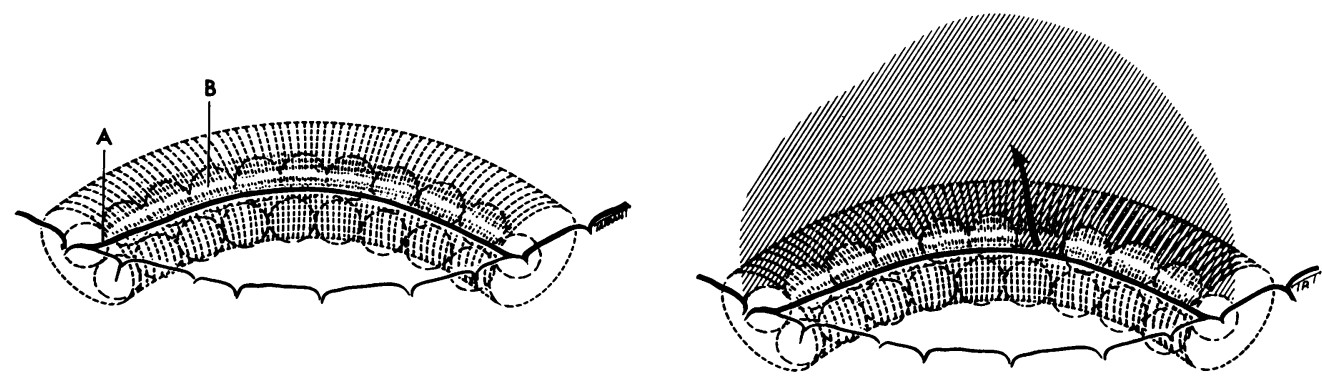

FIG. I Arrangement of the circumferential sponge and cryotherapy applications (dotted lines). Positioning of the sponge as shown will result in an indent with the maximum height along line $B$. This is seen to be posterior to the dialysis edge $A$. The ends of the sponge and the cryotherapy applications are extended to the ora serrata at both ends.

FIG. 2 A failed situation. Part of cryotherapy has been inadequate, allowing communication to be maintained between the dialysis edge and the subretinal fluid behind the sponge.

\section{Cryotherapy}

Particular points about the application of cryotherapy in these cases should be noted. In general, two rows of cryotherapy were needed. Particular care was taken to apply treatment to the ends of the dialyses and, because it is essential to achieve adhesion behind the edge of the dialysis, applications should be made so as to freeze posterior to the dialysis edge as well as to the edge and base of the dialysis (Fig. I). Care must be taken to avoid gaps in the cryotherapy which might allow subsequent leakage from the edge of the dialysis (Fig. 2, arrow), and this is particularly likely to occur in the more posterior applications when near the apex of the dialysis. If subretinal fluid is deep and it is not possible to oppose pigment epithelium to the detached part of the retina with the cryoprobe at operation, excessive cryotherapy may result in pigment fallout. This is particularly likely in these cases to occur at the macula, which has very often only just been elevated by the detachment (Chignell, Revie, and Clemett, I971). 


\section{RESULTS OF TREATMENT}

Of the 62 patients, six had had previous operations elsewhere. In five of these cases failure had occurred because the buckle was too anterior in placement. Of the 64 eyes with detachments treated by us, $54(84.5$ per cent.) were cured with the initial operation. A further eight cases (12.5 per cent.) were cured with a second procedure, making a final success rate in this series of 97 per cent. Two patients ( 3 per cent.) proceeded to total retinal detachment because of massive retraction of the vitreous, and subsequent re-attachment of the retina did not occur. None of the 62 successful cases has recurred so far in a follow-up period varying from $I$ to 5 years.

\section{Reasons for failure of the primary procedure}

In five of the ten cases requiring more than one operation (Table IV), the cryotherapy application was inadequately placed and a gap appeared at the apex of the dialysis. Two cases had failed because the placement of the buckle had been too anterior and a further failure occurred because an encirclement procedure had resulted in a very poor buckle. Re-attachment of the retina did not occur in two cases due to massive vitreous retraction. In both these cases, extensive preoperative preretinal fibrosis had been present. In all these failed cases there was persistence of subretinal fluid in the postoperative period, although it was invariably preceeded by some initial absorption.

Table IV Reasons for re-operation in ten cases of retinal dialysis

\begin{tabular}{ll}
\hline Reason & No. of cases \\
\cline { 1 - 1 } Inadequate cryotherapy & 5 \\
Buckle placed too anteriorly & 2 \\
Poor indentation & 1 \\
Massive vitreous retraction & 2 \\
\hline
\end{tabular}

\section{Treatment of the failed situation}

In the five cases in which cryotherapy had been inadequately applied, light coagulation was used postoperatively to fill in the defects. In all cases this resulted in prompt adhesion and subsequent complete absorption of retinal fluid. The time of application of light coagulation was from 7 to 10 days in the postoperative period. Two cases needed repositioning of the external sponge and the failed encirclement procedure was successfully cured by tightening the encircling band. In the two cases which developed massive vitreous retraction, further surgery failed to produce re-attachment.

\section{Cases treated without drainage of subretinal fluid}

Of the twenty detachments treated by this method, eighteen were immediately successful, and in the remaining two cases success was achieved by postoperative light coagulation in one case and adjustment of the external sponge in the other (also without drainage of subretinal fluid). In many of the cases treated in this manner, the buckle failed to close the dialysis completely at operation; closure occurred, however, within 24 hours of operation with subsequent absorption of subretinal fluid. In all cases the eventual height of the buckle has been found to be entirely adequate. 
53 eyes had preoperative detachment of the macula. In the remaining cases preoperative visual acuity was normal and therefore no improvement occurred after surgery. In cases with macular detachment, vision was deemed to have improved if the visual acuity had improved by at least two lines on the Snellen Test Chart up to at least I year from the time of surgery. In the 53 cases with macular detachment, visual acuity subsequently improved in 38 ( 78 per cent.). A comparison of improvement in visual acuity was then made between the cases treated with drainage of subretinal fluid and those treated without. Of the eighteen cases with detachment of the macula of less than 3 months' duration treated with drainage of subretinal fluid, the visual acuity subsequently improved in fifteen ( 83 per cent.). Of the seven cases with detachment of the macula of less than 3 months' duration treated without drainage of subretinal fluid, the visual acuity improved in five (7 I per cent.). There is no statistical difference $(P>0 \cdot I)$ in improvement of visual acuity between the two groups.

Of the twenty cases with detachment of the macula of more than 3 months' duration treated with drainage of subretinal fluid, the visual acuity improved in thirteen. Of the eight cases detached for more than 3 months treated without drainage of subretinal fluid, the visual acuity improved in three. There is no statistical difference $(P>0 \cdot I)$ in improvement of visual acuity between the two groups. In all the groups considered the ages were evenly distributed.

\section{Discussion}

The incidence of dialysis of 8 per cent. in this series is similar to the incidence of ro per cent. reported by Hagler and North (1968). Four cases ( 7 per cent.) were bilateral and were all in the lower temporal quadrant. The tendency for dialyses to occur in young emmetropic males as opposed to old myopic patients with equal sex distribution as described in non-traumatic detachments by Schepens and Marden (1966) is therefore confirmed. The insidious progress and lack of readily noticeable symptoms of detachments due to dialysis is well shown by the estimated length of the duration of detachment at presentation. Thus it was seen that only nine cases (14 per cent.) presented with a detachment considered to be less than 2 weeks in duration in addition to which 53 cases (84 per cent.) were found to have associated detachment of the macula. Even though there was no statistical evidence to show that the return of visual acuity is better in the cases treated without release of subretinal fluid, the successful re-attachment in these cases illustrates various points:

(I) The risk of most intraocular complications is completely avoided with this entirely extraocular procedure. With the exception of extraocular infection (Lincoff, Nadel, and O'Connor, 1970), the local episcleral sponge was found to be entirely satisfactory and it has not been found necessary to perform a procedure involving scleral dissection in any case.

(2) Longstanding inferior detachments are not in their own right an indication for drainage of sub-retinal fluid. Spontaneous reabsorption will occur again in the postoperative period and these findings support the observations of Nadel and others ( 197 I).

(3) It is not always possible or necessary to close the hole completely at the time of surgery. Correct placement of the buckle will result in apposition within 24 to 48 hours with subsequent absorption of subretinal fluid. The height of the buckle used in this technique has been found to be entirely adequate. 
(4) In view of the success of local procedures, encirclement should be reserved only for exceptional cases (e.g. giant dialyses, vitreous fibrosis).

\section{Summary}

62 patients (66 dialyses) with retinal detachments due to dialyses are considered and the main clinical features of this series discussed. The macula was detached preoperatively in 53 cases (84 per cent.) and of these cases improvement in visual acuity was achieved in 38 (72 per cent.). 54 cases were cured by the initial procedure, while a further eight needed a second procedure, resulting in an overall success rate of 97 per cent. of which there have been no recurrences to date. Two cases failed because of massive vitreous retraction resulting in total retinal detachment. In considering some aspects of the surgical technique used in local buckling, emphasis was laid upon the placement of the implant and the application of cryotherapy to achieve adhesion behind the dialysis edge and at its extremities is described. The reasons for, and the treatment of, failure is discussed.

Twenty cases were treated with local episcleral plombage and cryotherapy alone without drainage of subretinal fluid.

The advantages of this method, avoiding the complications of drainage of subretinal fluid, are stressed, and it seems likely that this technique can be used in the treatment of the majority of dialyses.

I am grateful to Mr. L. G. Fison for permission to study his patients, to Mr. T. Tarrant of the Audiovisual Communications Department of the Institute of Ophthalmology for preparing diagrams, and to Miss M. Farrell for secretarial assistance. This work was in part supported by the Clothworkers' Company.

\section{References}

BLACH, R. K., and DAvies, E. W. G. (I967) Trans. ophthal. Soc. U.K., 87, 317

CHIGNELl, A. H., REVIE, I. H. S., and Clemett, R. s. (I97I) Ibid., 91, 635

cox, M. S., sChepens, c. L., and freEman, H. M. (1966) Arch. Ophthal. (Chicago), 76, 678

GROCK, G. (1967) Trans. ophthal. Soc. U.K., 87, 513

DUfour, R. (1969) Mod. Probl. Ophthal., 8, 358. (Bibliotheca ophthalmologica, Fasc. 79)

haGler, w. S., and NORTh, A. w. (1968) Arch. Ophthal. (Chicago), 79, 376

HUDson, J. R. (1965) Trans. ophthal. Soc. U.K., 85, 79

LEFFERSTRA, L. J. (1950) Ophthalmologica (Basel), I19, I

Lincoff, H. A., and kreissig, I. (1972) Trans. Amer. Acad. Ophthal. Otolaryng., 76, I22 I

- NADEl, A., and o'connor, P. (1970) Arch. Ophthal. (Chicago), 84, 42 I

NADEL, A., GIESER, R., and Lincoff, H. A. (197I) Ann. Ophthal., 3, I3I I

SCHEPENS, C. L., and MARDEN, D. (1966) Amer. F. Ophthal., 6r, 2 I 3

scoTt, J. D. (1970) Trans. ophthal. Soc. U.K., 90, 57 